\title{
Prevalence and associated factors of chlamydial infection among patients seeking clinic-based STI services in Shenzhen, China
}

Hong-Lin Wang

Shenzhen Center for Chronic Disease Control, Guangdong Province

Yu-Mao Cai ( $\nabla 4165469 @ q q . c o m$ )

Shenzhen Center for Chronic Disease Control https://orcid.org/0000-0002-8098-8244

\section{Xiang-Sheng Chen}

Chinese Academy of Medical Sciences \& Peking Union Medical College Hospital of Skin Diseases and Institute of Dermatology

Wei-Ye Yu

Baylor College of Medicine

\section{Fu-Chang Hong}

Shenzhen Center for Chronic Disease Control

\section{Tie-Jian Feng}

Shenzhen Center for Disease Control and Prevention

Jin-Hong Liu

Shenzhen Center for Chronic Disease Control

Chun-Lai Zhang

Shenzhen Center for Chronic Disease Control

\section{Li-Zhang Wen}

Shenzhen Center for Chronic Disease Control

\section{Feng Wang}

Shenzhen Center for Chronic Disease Control

Jian-Bin Ye

Shenzhen Center for Chronic Disease Control

\section{Rong-Xing Weng}

Shenzhen Center for Chronic Disease Control

Fen Tang

Shenzhen Center for Chronic Disease Control

\section{Research article}

Keywords: Chlamydia trachomatis, STI surveillance programming, intervention, resource allocation, China 
Posted Date: July 16th, 2020

DOI: https://doi.org/10.21203/rs.2.21284/v2

License: (c) (i) This work is licensed under a Creative Commons Attribution 4.0 International License. Read Full License 


\section{Abstract}

The authors have withdrawn this preprint due to erroneous posting. 